\title{
Test Research on Progressive Collapse Resistance of Aluminium Alloy Honeycomb Panel-rod Composite Latticed Shell
}

\author{
Zhewen Wang ${ }^{1, *}$, Caiqi Zhao ${ }^{2}$ \\ ${ }^{1}$ School of Civil Engineering, Southeast University, 211189 Nanjing, China \\ ${ }^{2}$ Key Laboratory of Concrete and Prestressed Concrete Structure of Ministry of Education, Southeast University, 211189 Nanjing, China
}

\begin{abstract}
In order to study the progressive collapse resistance of the panel-rod composite latticed shell, a static test was performed on two latticed shells with the same size, one of which was removed a key member. The results of experiments and numerical simulations show that the composite reticulated shells were damaged due to the fracture of some members and the shearing of some rivets. Compared with the complete latticed shell, the bearing capacity of the latticed shell which was removed a key member did not decrease too much, but its displacement of the joints increased significantly. The phenomenon indicated that the removal of the key member had a certain effect on the progressive collapse resistance of the composite latticed shell. The key members of the composite latticed shell must be locally strengthened.
\end{abstract}

\section{Introduction}

The occurrence of the 911 incident in the United States makes people focus on progressive collapse [1]. In the past few years, many countries have formulated the related regulations. The latticed shell is widely used in the public buildings such as stadiums and warehouses [2]. Once progressive collapse occurs, it can make terrible consequences. Many scholars have studied the problem of resistance to progressive collapse. At present, the researches on the resistance to progressive collapse mainly focus on the frame structures and steel structures [3-5], and some scholars have studied the latticed shell [6-8]. However, the researches on the aluminium alloy honeycomb panel-rod composite latticed shell are relatively limited.

The honeycomb panel is composed of one honeycomb core layer in the middle and two thin upper layers. Due to its high specific strength and good impact resistance, it has been gradually applied to the bridge and maintenance engineering [9-10]. At present, honeycomb panels are mainly hexagonal honey comb sandwich structures. In order to improve the bearing capacity and stability of the aluminium alloy latticed shell, this paper proposes to combine the aluminium alloy mesh shell and the aluminium alloy honeycomb panel to form a new panel-rod composite latticed shell structure. Preliminary research shows that under the same conditions, the panel-rod composite latticed shell significantly improves the stability and ultimate bearing capacity of aluminium alloy latticed shells [11].

This paper presents a static test to study the resistance of aluminium alloy honeycomb panel-rod composite latticed shell. Two cylindrical composite latticed shells with the same size were tested, one of which was removed one key member. Therefore, by comparing the results of two latticed shells, collapse resistance mechanism of the panel-rod composite latticed shell can be revealed.

\section{Test programs}

\subsection{Model design}

The cylindrical composite latticed shells used $\mathrm{T}$-shape members, and the dimension of members' cross section was $50 \times 50 \times 3 \times 3 \mathrm{~mm}$. The mechanical properties of members were shown in Table 1. 12.9-level screws were used between the members and the steel joints through screw holes to fix the members. The size of the honeycomb panel was $800 \times 720 \times 10 \mathrm{~mm}$. The members and the honeycomb panels were connected by rivets. The cylindrical composite latticed shells had a total length of $4.4 \mathrm{~m}$, a width of $1.53 \mathrm{~m}$ and a height of $1.1 \mathrm{~m}$. There were 32 members (one of the tested latticed shells was removed one key member), 21 joints and 12 honeycomb panels. The geometric properties of the tested latticed shells were shown in Fig. 1.

Table 1. Mechanical properties of members.

\begin{tabular}{|c|c|c|c|}
\hline $\begin{array}{c}\text { Elastic } \\
\text { Modulus } \\
E(\mathrm{GPa})\end{array}$ & $\begin{array}{c}\text { Shear } \\
\text { modulus } \\
G(\mathrm{GPa})\end{array}$ & $\begin{array}{c}\text { Yield strength } \\
f_{y}(\mathrm{MPa})\end{array}$ & $\begin{array}{c}\text { Ultimate } \\
\text { strength } f_{u} \\
(\mathrm{MPa})\end{array}$ \\
\hline 70 & 27 & 240 & 290 \\
\hline
\end{tabular}

\footnotetext{
* Corresponding author: zhewen_wang@163.com
} 


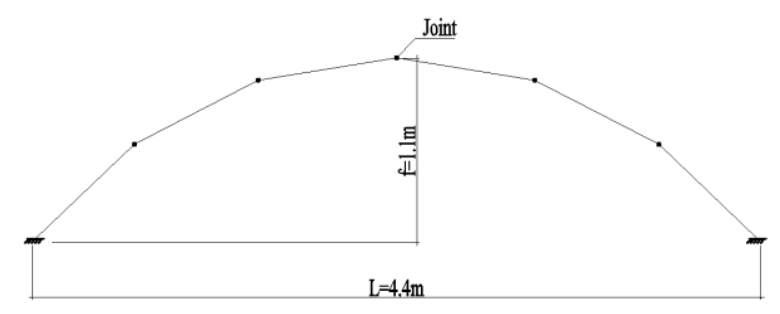

(a) Side view of the tested latticed shells.

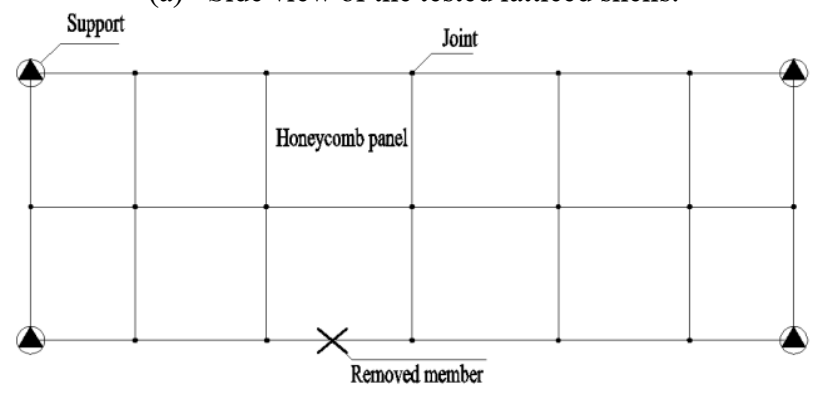

(b) Plan view of the tested latticed shells.

Fig. 1. Overview of the tested latticed shells.

\subsection{Test setup}

Fig. 2 presented the support setup. In order to prevent the sudden damage of the latticed shells, the supports of the cylindrical composite latticed shells were welded with steel plates, and the steel plates were fixed with four steel bars.

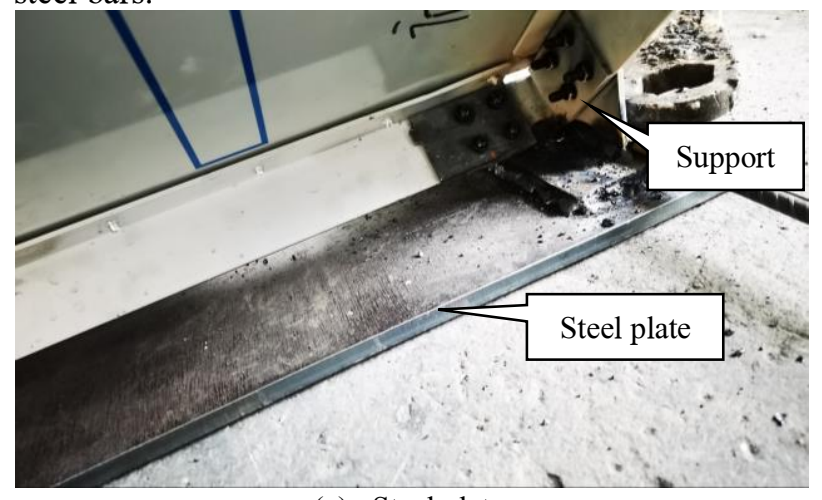

(a) Steel plate

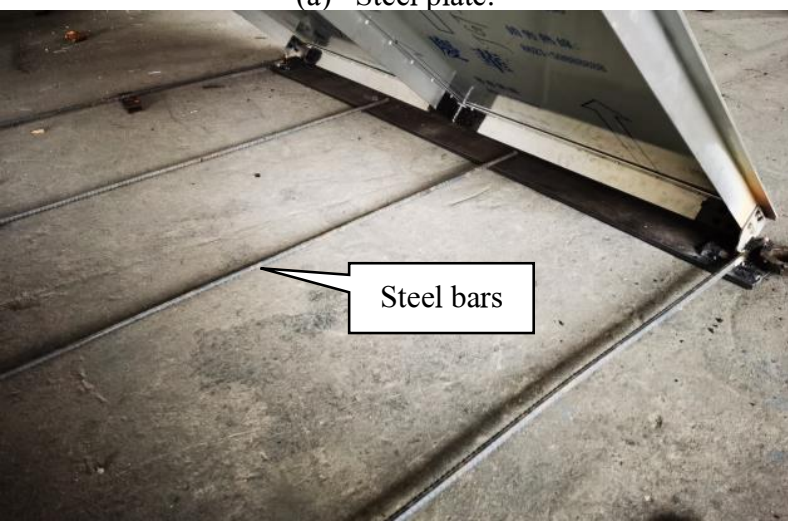

(b) Steel bars.

Fig. 2. Overview of the tested latticed shells.

When arranging the displacement measuring points, this paper considered the following factors:(1) Due to the large displacements near the loading points, the displacement measuring points were added in this area;(2) Displacement check points were appropriately arranged at some symmetrical positions of the test latticed shells; (3) In order to prevent large displacements at the supports, monitoring points were set at two supports. The displacement measuring points were shown in Fig. 3. The whole setup of the cylindrical composite latticed shells was shown in Fig. 4.

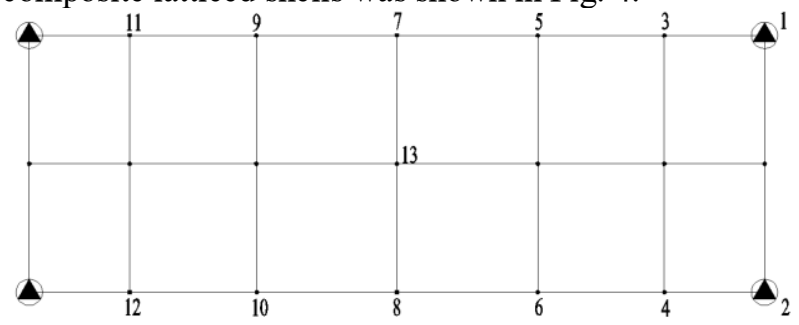

Fig. 3. displacement measuring points of the tested latticed shells.
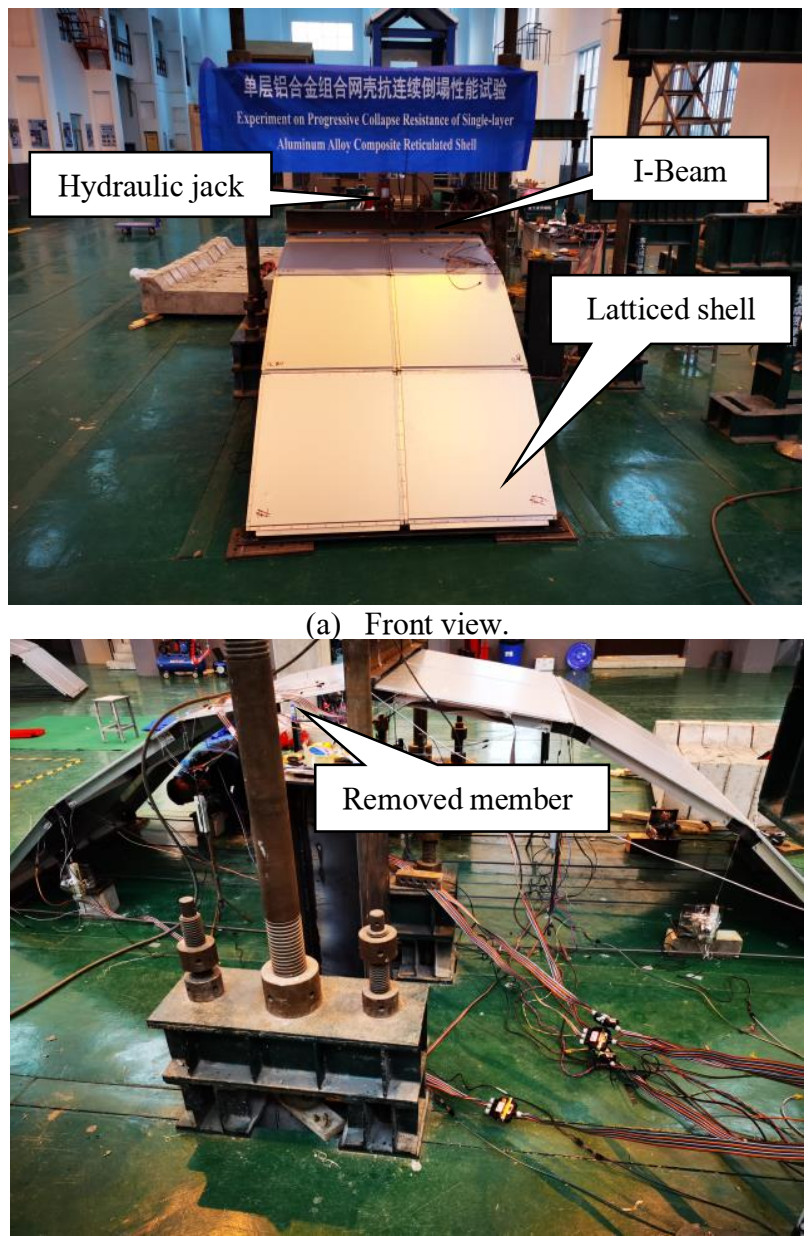

(b) Side view.

Fig. 4. Test setup.

\subsection{Instrumentation}

Firstly, loading device of the test was a hydraulic jack. The jack exerted a vertical downward force on a I-beam, and then the I-beam transmitted the force to the cushion block to perform two-point loading on the composite latticed shells. The hydraulic jack recorded the bearing capacity data at all times. Fig. 5 presented the loading arrangement. 


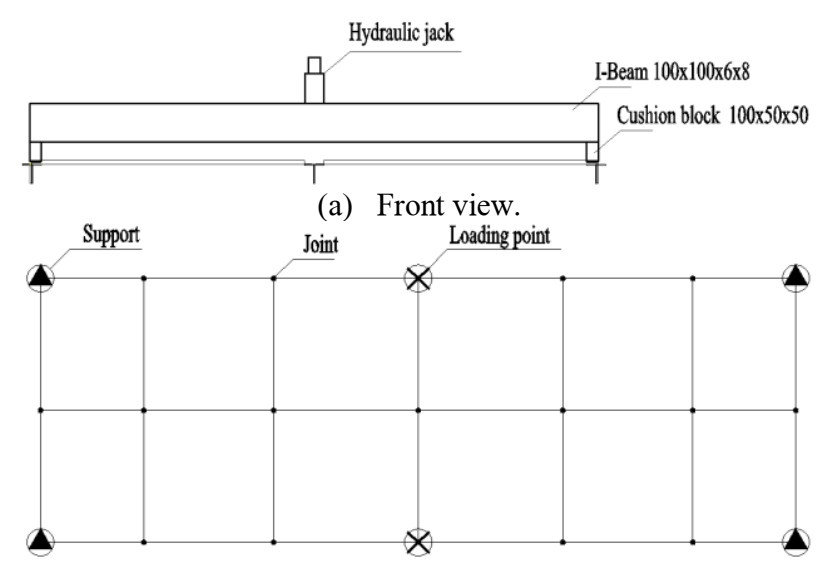

(b) Plan view.

Fig. 5. Loading arrangement of the tested latticed Shell.

Furthermore, the displacement data of the tested latticed shells were collected by YWD-100 and YWD200 displacement meters. During the test, the instrument automatically collected data and transmitted it to the computer.

\section{Test results}

\subsection{The complete composite latticed shell}

In the early stage of loading, when the load was less than $4500 \mathrm{~N}$, the tested model was in the elastic phase, and the load increased linearly with the displacement. As the load increased, the test model entered the plastic phase. When the vertex displacement reached $49 \mathrm{~mm}$, the structure buckled, and the structural bearing capacity was $6604 \mathrm{~N}$. At this time, if continuing increasing the load, the structural displacement would increase sharply, because part of the members were broken and lost its bearing capacity, and some joints were broken. Some rivets are pulled off or sheared, and the member and honeycomb panel no longer worked together. Fig.6 presented the destructive view of the complete composite latticed shell.

\subsection{The composite latticed shell which was removed one key member}

In the early stage of loading, when the load was less than $4000 \mathrm{~N}$, the tested model was in the elastic phase, and the load increased linearly with the displacement. As the load increased, the test model entered the plastic phase. The displacement in the removed member was larger than other areas. When the vertex displacement reached $64 \mathrm{~mm}$, the structure buckled and the maximum bearing capacity of the structure was $6698 \mathrm{~N}$. At this time, if continuing increasing the load, the displacement of the composite latticed shell would increase sharply, because part of the members were broken and lost the bearing capacity. The rivets were pulled off or sheared. Fig. 7 presented the destructive view of the composite latticed shell which was removed one key member. Fig.8 presented the part of the broken components of two latticed shells.

\subsection{Compared with the FE analysis}

This paper used the finite element software named ANSYS to conduct numerical simulation.

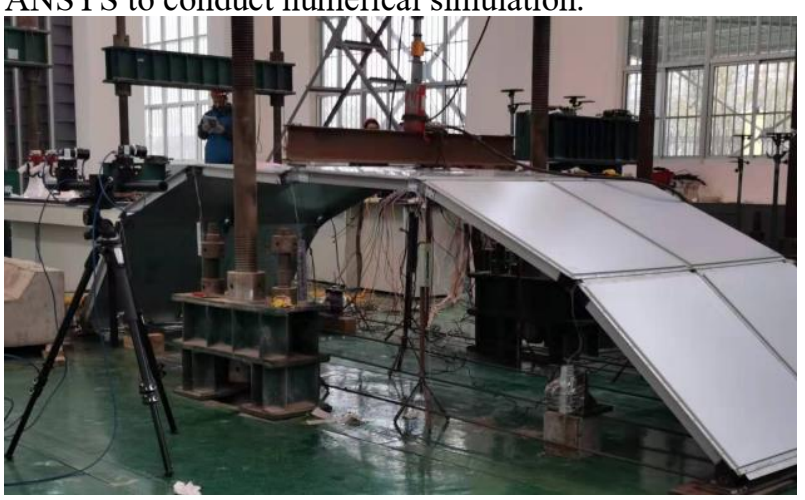

(a) Destructive view 1 .

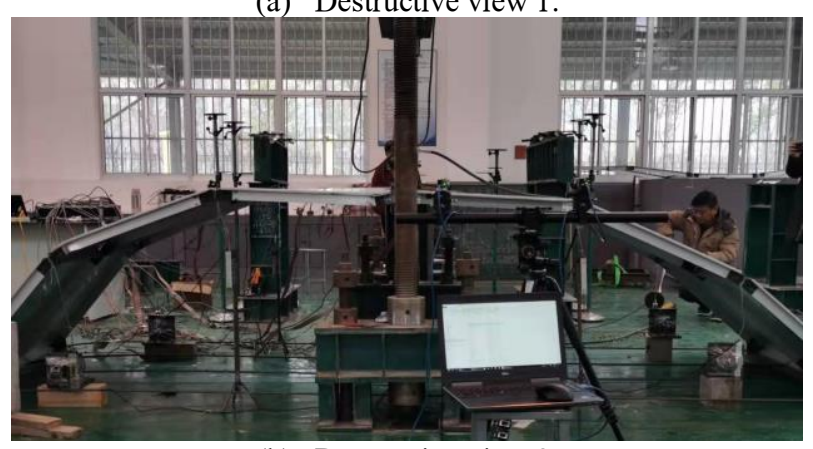

(b) Destructive view 2 .

Fig. 6. Destructive view of the complete latticed shell.

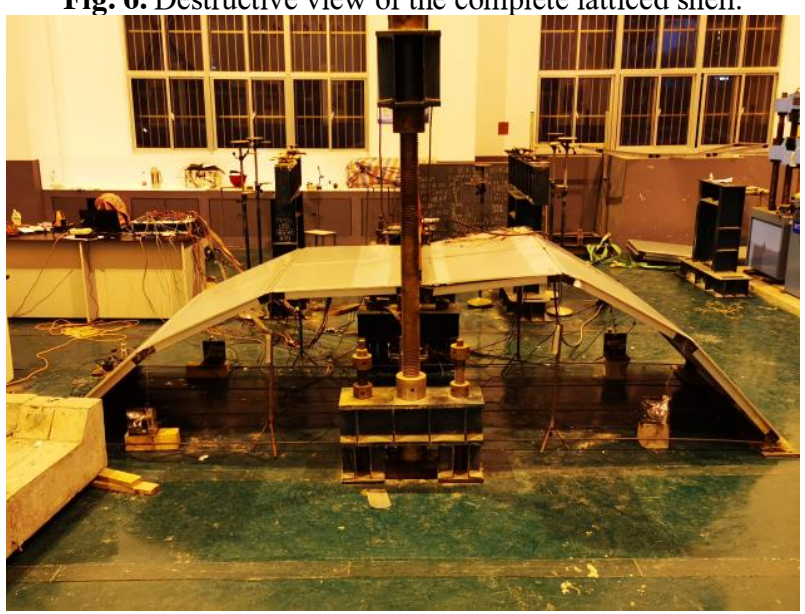

(a) Destructiive view 1

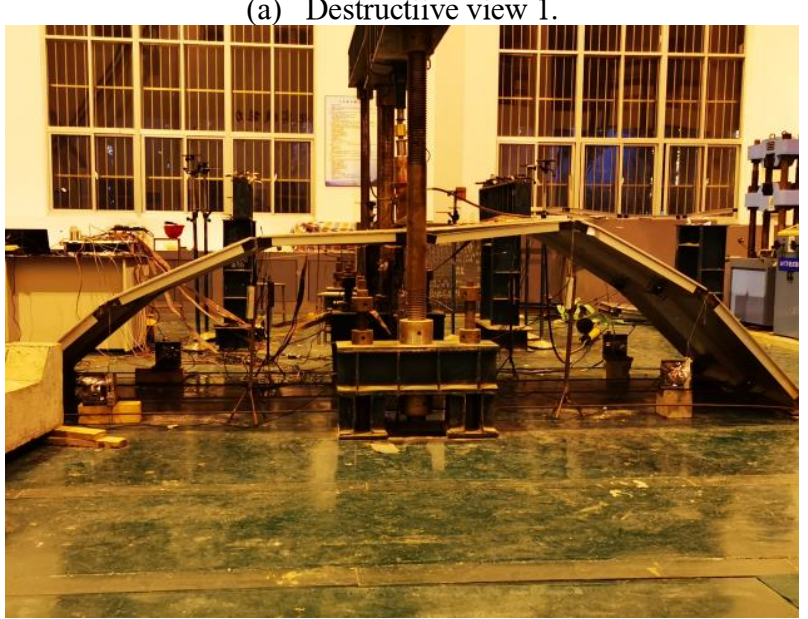

(b) Destructive view 2 .

Fig. 7. Destructive view of the incomplete latticed shell. 


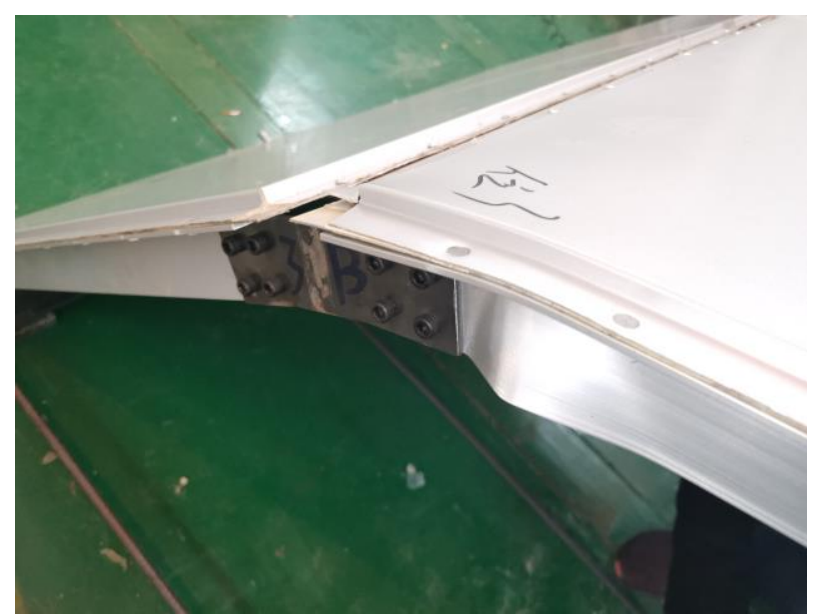

(a) Buckling member.

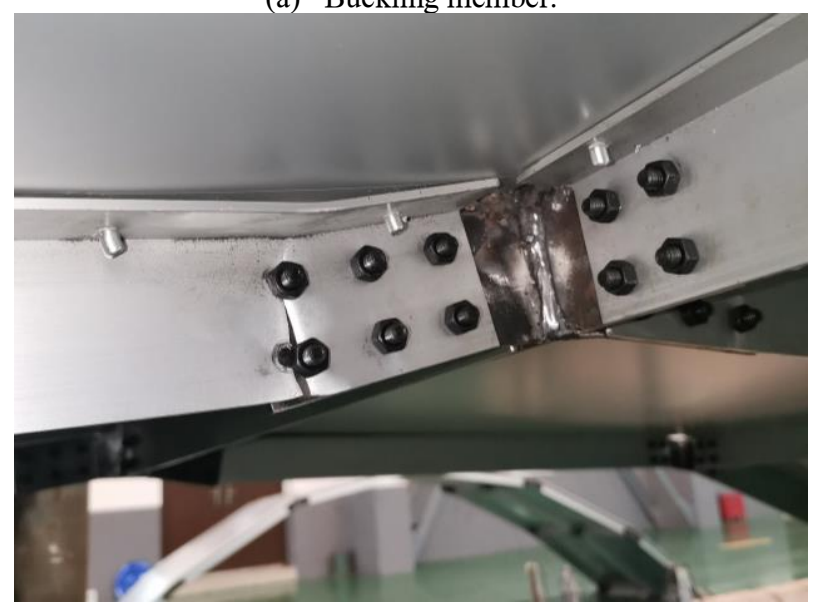

(b) Broken member.

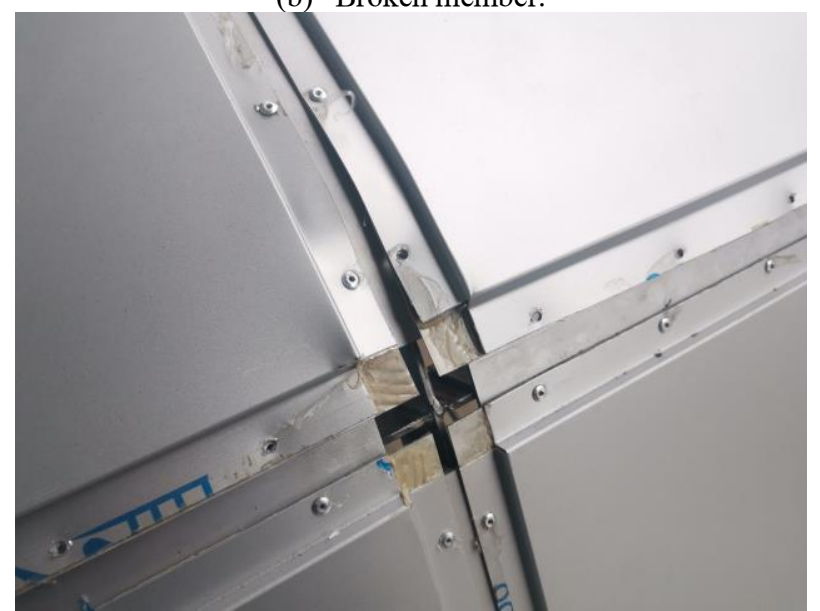

(c) Broken rivets.

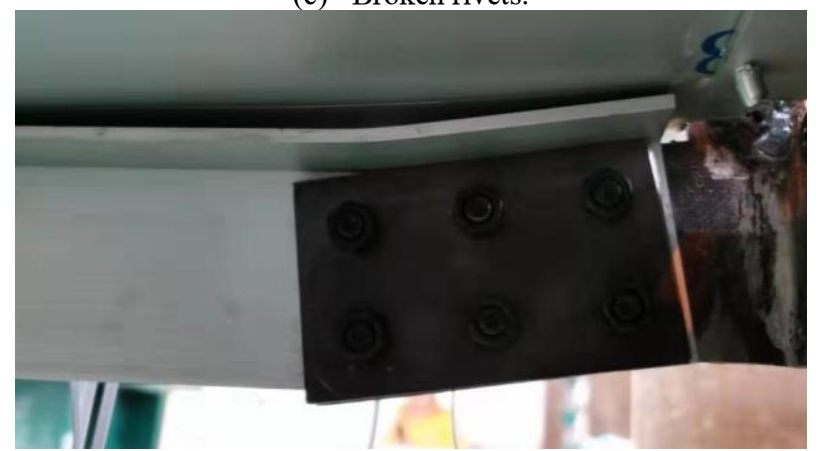

(d) Broken joint.

Fig. 8. Part of the broken components.
Due to the complex structure of the honeycomb panel, equivalent modelling of the honeycomb panel was required. The common equivalent methods of honeycomb panels were sandwich panel theory, honeycomb panel theory and equivalent panel theory [12]. In this paper, the equivalent panel theory based on Reissner Theory was used for the subsequent numerical simulation. Table 2 presented the equivalent parameter of the honeycomb panel.

Table 2. Equivalent parameter of the honeycomb panel.

\begin{tabular}{|c|c|c|c|}
\hline $\begin{array}{c}\text { Equivalent } \\
\text { thickness } \\
t_{e q}(\mathrm{~mm})\end{array}$ & $\begin{array}{c}\text { Equivalent } \\
\text { elastic } \\
\text { modulus } \\
E_{e q}(\mathrm{GPa})\end{array}$ & $\begin{array}{c}\text { Equivalent } \\
\text { Poisson's } \\
\text { ratio } \mu_{e q}\end{array}$ & $\begin{array}{c}\text { Equivalent } \\
\text { density } \\
\rho_{e q}\left(\mathrm{~kg} / \mathrm{m}^{3}\right)\end{array}$ \\
\hline 15.588 & 8.981 & 0.33 & 381.194 \\
\hline
\end{tabular}

Fig. 9 presented the latticed shells' failure modes of the finite element simulation. It was obvious that they were similar with the test results. Test and finite element results of some measuring points' vertical displacements were shown in Fig. 10. As Fig. 10 showed, in the elastic stage, the test value was very close to the finite element simulation value, and the error limit was no more than $10 \%$. The curve of the finite element simulation value was relatively smooth, while the fluctuation of the test value was relatively obvious; After entering the plastic stage, the error between the test value and the finite element simulation value increased gradually. The maximum bearing capacity of the finite element

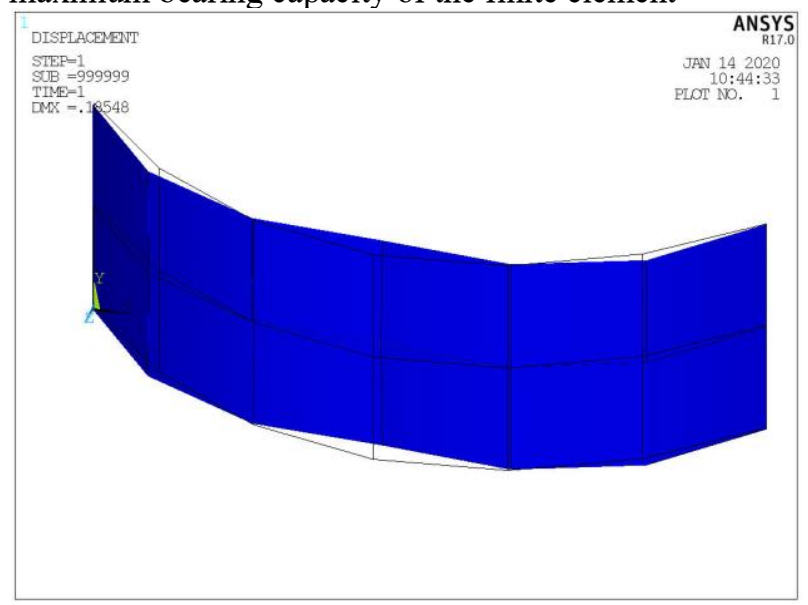

(a) Plan view of the complete latticed shell. 


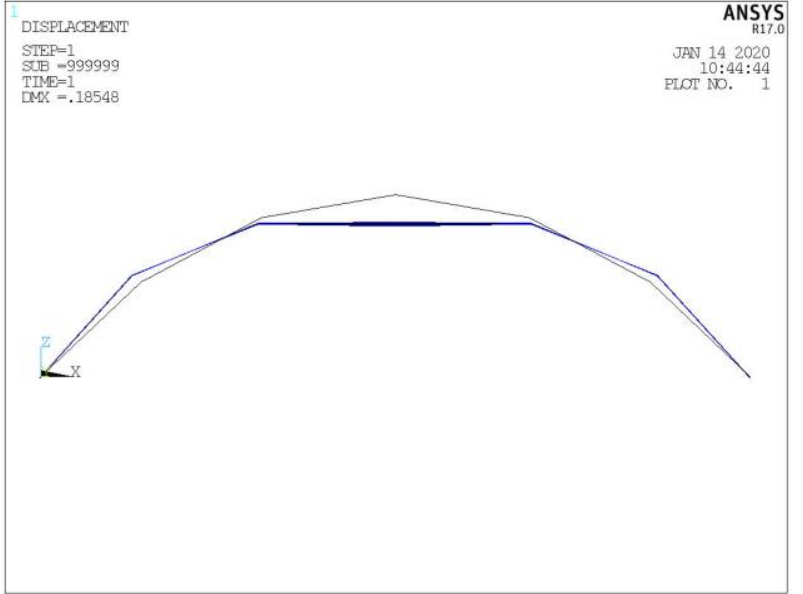

(b) Side view of the complete latticed view.

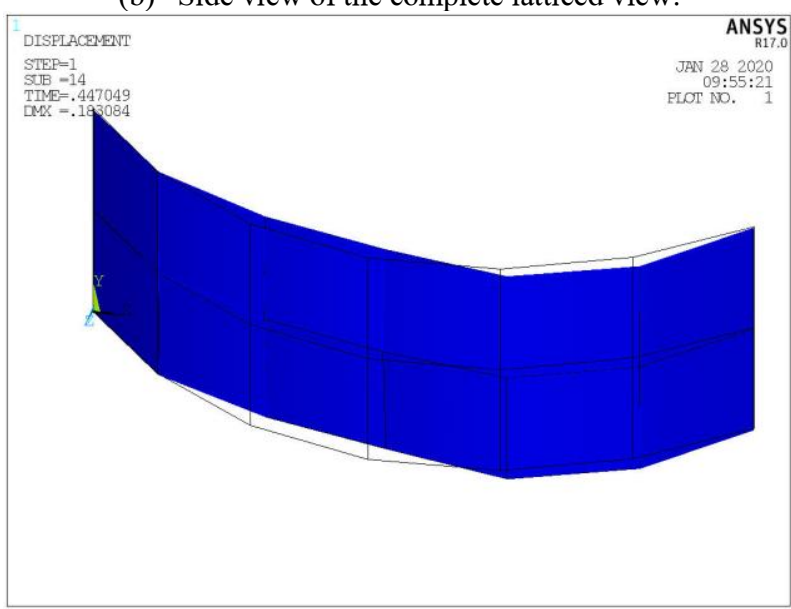

(c) Plan view of the incomplete latticed shell.

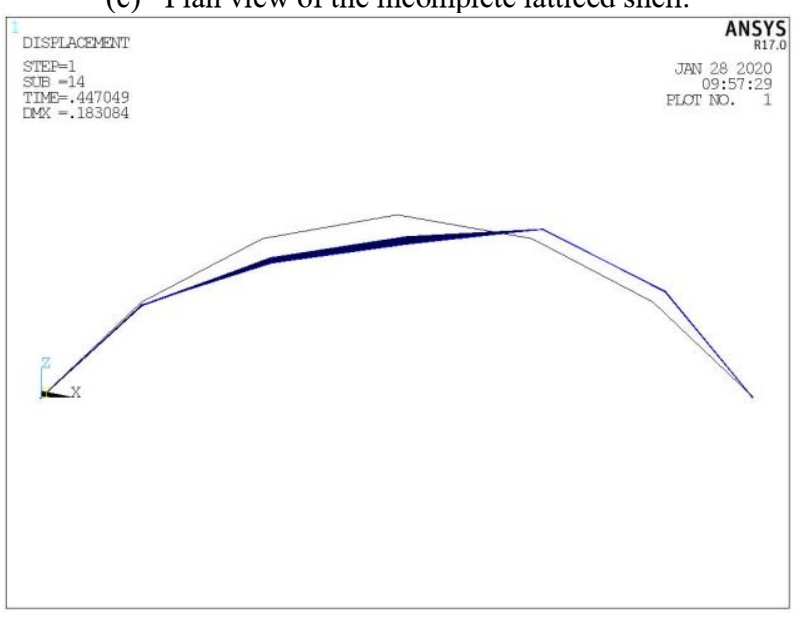

(d) Side view of the incomplete latticed shell.

Fig. 9. Failure modes of the finite element simulation.

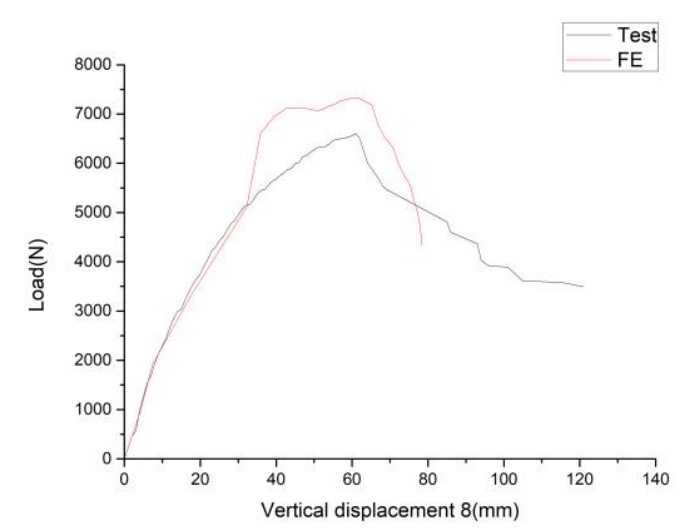

(a) Measuring point 8 of the complete latticed shell.

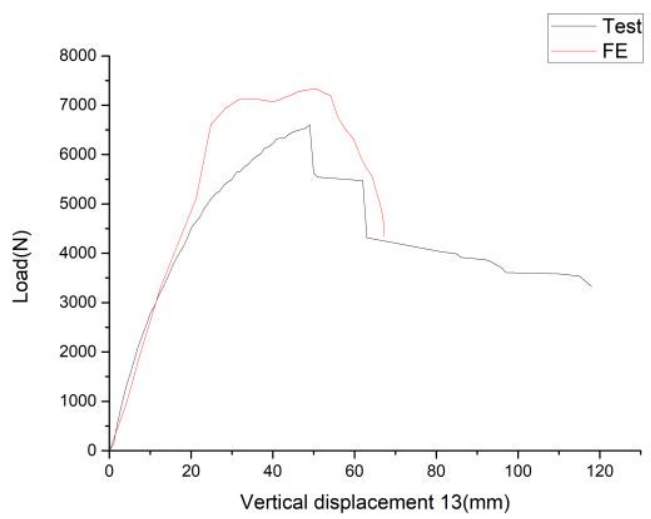

(b) Measuring point 13 of the complete latticed shell.

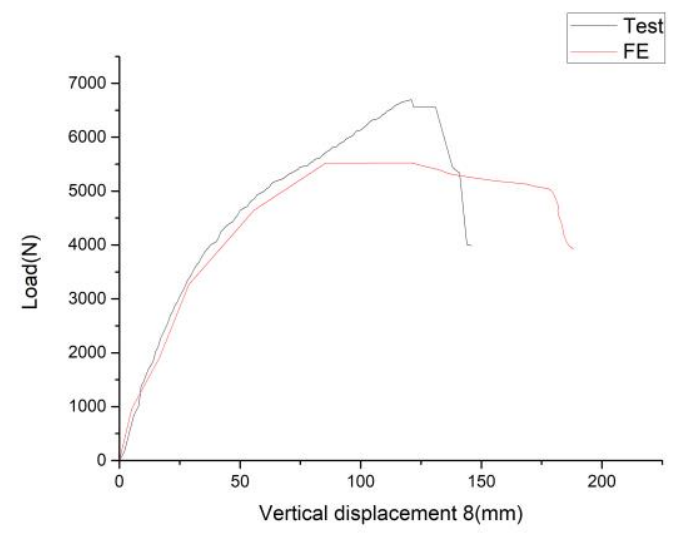

(c) Measuring point 8 of the incomplete latticed shell.

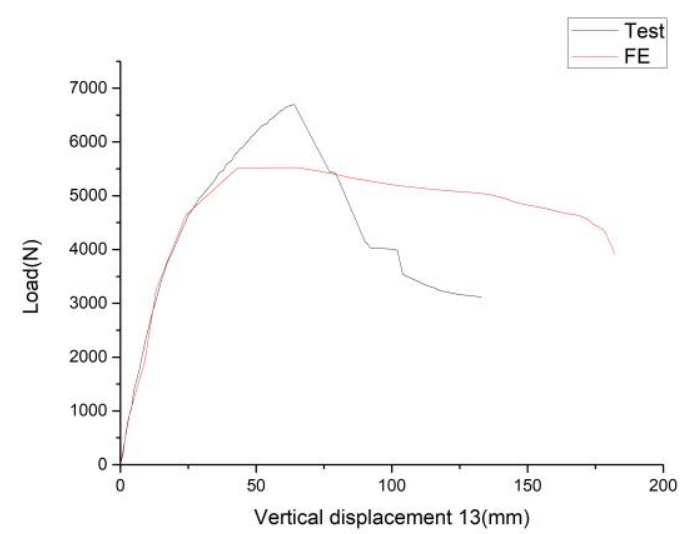

(d) Measuring point 13 of the incomplete latticed shell.

Fig. 10. Vertical displacements of the measuring points. 
simulation of the complete latticed shell was larger than that of the test value, because the finite element simulation used the complete coordination method, the constraints between the panels and members were larger than the tested model; the maximum bearing capacity of the test of the incomplete latticed shell was larger than that of the finite element simulation, because the joints and the honeycomb panels did not deformed together during the test and the joints bore part of the bearing capacity, which didn't lead to sudden failure in the area without the key member. Fig. 11 presented the joint deformation in the area without the key member during the test. In the load decline stage, the test value dropped rapidly, which was caused by the fracture of some

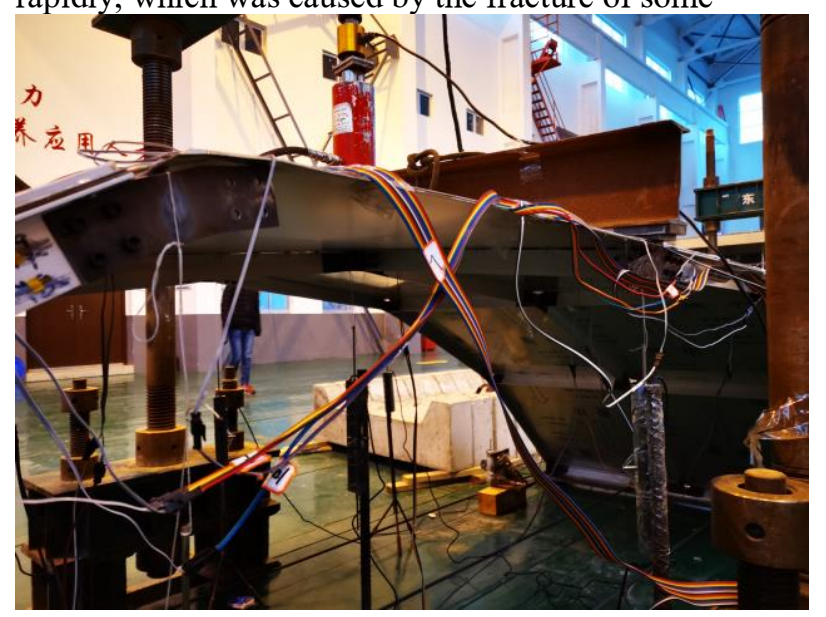

Fig. 11. Joints in the area without the key member.

members and the sheared rivets, while the finite element simulation value dropped gently, because the honeycomb panels and members always worked together in the finite element simulation to ensure the ideal working state.

\section{Conclusions}

In this paper, two cylindrical composite latticed shells of the same size were tested and compared. One of the latticed shells was removed one key member. According to the analysis results, the following conclusions are obtained:

(1) The removal of one key member took little effect on the ultimate bearing capacity of the cylindrical composite latticed shell, but the displacement of the incomplete latticed shell is about 30\% larger than that of the complete one at the same measuring point. The deformation degree of the incomplete latticed shell was larger than that of the complete latticed shell and the incomplete latticed shell entered plastic stage faster than the complete one. Therefore, the removal of one key member could lead to degradation of progressive collapse resistance of the composite latticed shell.

(2) Because the test was loaded by a manual jack, the test loading curve was not smooth and the fluctuation was obvious; there were machining errors and transport losses during the test, which would cause some errors between the test value and the finite element simulation value. The average error of test value and numerical simulation value could be controlled within $10 \%$, and the failure modes of two cylindrical composite latticed shells were basically the same as those of finite element simulation. Therefore, FE analysis could be used to evaluate the progressive collapse resistance of the composite latticed shell.

\section{Acknowledgement}

The work presented in this paper was funded by the National Natural Science Foundation of China (No. 51578136). The help provided by $\mathrm{Ye} \mathrm{Gu}$ (Southeast University) and Kun Qian (Southeast University) during the test program was also acknowledged.

\section{References}

1. J. Cai, F. Wang, J. Feng, et al, Several Issues in Progressive Collapse Analysis of Long-span Spatial Structures, Engineering Mechanics, 03:153-159 (2012)

2. H. Liu, Y. Ding, Z. Chen, Static Stability Behaviour of Aluminium Alloy Single-layer Spherical Latticed Shell Structure with Temcor Joints, Thin-Walled Structures, 120 :355-365(2017)

3. Y. Liang, X. Lu, Y. Li, et al, The Influence of Floor Slabs on the Progressive Collapse Resistance of Structures, Sichuan Building Science Research, 02 :5-10(2010)

4. S. Li, Y. Zhao, C. Zhao, et al, Study on the Influence of Nodes on the Progressive Collapse Resistance of RC Frame Structures, Engineering Mechanics, 29(12) :80-87(2012)

5. Y. Zheng, D. Zou, T. Yang, Analysis of Progressive Collapse Resistance of Steel Structure Based on Catenary Theory, Steel Structure, 27(9) :11-15(2012)

6. Q. Han, M. Liu, Y. Lu, et al, Progressive Collapse Analysis of Large-span Reticulated Domes, International Journal of Steel Structures,15(2) :261269(2015)

7. X. Zhao, S. Yan, Y. Chen, Comparison of Progressive Collapse Resistance of Single-layer Latticed Domes under Different Loadings, Journal of Constructional Steel Research, 129 :204214(2017)

8. L. Tian, J. Wei, J. Hao, Optimisation of Long-span Single-layer Spatial Grid Structures to Resist Progressive Collapse, Engineering Structures, 188:394-405(2019)

9. J. Davalos, P. Qiao,X. Xu, et al, Modeling and Characterization of Fiber-reinforced Plastic Honeycomb Sandwich Panels for Highway Bridge Applications, Composite Structures, 52(3):441452(2001) 
10. X. Liu, G. Tong, Y. Zhou, A Review of design Methods of Ultralight Porous "Honeycomb-like" Sandwich Structures, Journal of Hebei University of Science and Technology, 36(1) :16-22(2015)

11. K. Gong, Study on the Stability of Aluminium Alloy Honeycomb Panel-rod Single-layer Combined Latticed Shell, Southeast University (2016)

12. L. Xia, X. Jin, Y. Wang, Equivalent Calculation of Satellite Structure Honeycomb Sandwich Panel, Journal of Shanghai Jiaotong University, 37(7) :9991001(2003) 